\title{
SUBSTRATOS PARA O ENRAIZAMENTO \\ DE MICROESTACAS DE MIRTILEIRO \\ CULTIVAR GEORGIAGEM ${ }^{1}$
}

\author{
NARA CRISTINA RISTOW ${ }^{2}$, LUIS EDUARDO CORREAA ANTUNES ${ }^{3}$, SÍLVIA CARPENEDO ${ }^{4}$
}

RESUMO - O objetivo do trabalho foi verificar a viabilidade e definir um substrato adequado para o enraizamento de microestaquia e o crescimento de mudas de mirtileiro cultivar Georgiagem. Foram avaliados diferentes substratos para a técnica de microestaquia mantida em condições de microambiente úmido, com temperatura e luz controladas. As microestacas foram acondicionadas em caixas de politereftalato de etileno, durante 48 dias. Os substratos turfa de musgo Sphagnum sp. e as misturas turfa + perlita, turfa + perlita + fibra de coco, turfa + perlita + serragem permitiram a obtenção de maior percentual de enraizamento. Termos de indexação: substratos, rejuvenescimento, Vaccinium, microestaquia, Southern highbush.

\section{SUBSTRATES FOR ROOTING MICROCUTTING BLUEBERRRY CULTIVAR GEORGIAGEM}

\begin{abstract}
The aim this research was check the viability end to determine a suitable substrate for rooting by microcutting technique and blueberry plant growth cultivar Georgiagem. The microcuttings were kept under moist micro-environment conditions at both regulated temperature and light. The microcuttings were kept in to boxes of ethylene polvtereftalate, during 48 days. The substrates Sphagnum sp. peat moss and the mixes of peat + perlite, peat + perlite + coconut fiber and peat + perlite + sawdust allowed higher rooting percentage.
\end{abstract}

Index terms: substrate, rejuvenation, Vaccinium, microcutting, Southern highbush.

\section{INTRODUÇÃO}

O cultivo do mirtileiro (Vaccinium spp.), nativo da América do Norte, está em franca expansão em países da América do Sul, como Chile, Argentina e Uruguai (ANTUNES et al., 2008). O crescimento das áreas cultivadas deve-se ao aumento do consumo de produtos saudáveis e com alto potencial antioxidante (PANNUNZIO et al., 2011).

Devido às atuais oportunidades de mercado, as perspectivas de cultivo do mirtileiro nos países do Hemisfério Sul são bastante animadoras, especialmente devido à época de colheita coincidir com a entressafra dos países maiores produtores e consumidores (SANTOS, 2004).

A propagação do mirtileiro pode ser realizada por sementes, enxertia ou estaquia. Dos meios disponíveis para se propagar mirtileiro, a estaquia é a mais usada (RISTOW, 2009). A miniestaquia e a microestaquia são técnicas de rejuvenecimento usadas com êxito na propagação de outras espécies, como eucalipto (WENDLING; DUTRA, 2010; DUTRA; WENDLING, 2010), o que possibilita consideráveis ganhos, decorrentes, principalmente, do aumento dos índices de enraizamento e da redução do tempo para a formação das mudas, pelo uso de propágulos com maior grau de juvenilidade (SCHUCH et al., 2008; RISTOW et al., 2009). Trabalhos realizados com Vaccinium meridionale Swartz mostraram que as estacas lenhosas não exibem atividade rizogênica depois do tratamento com AIB e AIA (LIGARRETO et al., 2006; CASTRILLÓN et al., 2008), mostrando maior viabilidade para o uso de estacas com maior grau de juvenilidade.

O sistema radicular do mirtileiro é superficial e caracterizado por ter raízes primárias muito finas, fibrosas e sem pelos radiculares. O substrato é um fator de grande importância na propagação do mirtileiro (WILLIANSON; MILLER, 2009). Tanto para multiplicação por estacas, como por micropropagação, as plantas devem ser enraizadas em um substrato com misturas adequadas. Têm-se usado, com êxito, turfa, misturas de turfa e areia, turfa e

${ }^{1}$ (Trabalho 071-11). Recebido em: 08-02-2011. Aceito para publicação em: 01-11-2011.

${ }^{2}$ Eng. Agrônoma, Doutora em Ciência - Área de concentração Fruticultura de Clima Temperado pela Universidade Federal de Pelotas FAEM/UFPel - E-mail: ncristow@hotmail.com

${ }^{3}$ Eng. Agrônomo, Doutor, Pesquisador Embrapa Clima Temperado, - Cx. P.403 - 96001-970 - Pelotas-RS - Bolsista CNPq, E-mail luis.eduardo@cpact.embrapa.br

${ }^{4}$ Eng. Agrônoma, Mestre em Fitotecnia, Universidade Federal de Pelotas FAEM/UFPel. - Pelotas-RS - E-mail: carpenedo.s@hotmail.com 
vermiculita, serragem e areia, sendo a turfa e a perlita mais comumente usadas (TREVISAN et al., 2008; XIE; TONG, 2009).

A caracterização físico-química dos substratos e seus componentes são necessários para a formulação da mistura, recomendações e monitoramento das fertilizações. A fibra de coco apresenta ótima aeração, aliada a uma boa capacidade de retenção de água (WENDLING; GATTO, 2002) e tendência de fixar cálcio e magnésio, liberar potássio no meio, $\mathrm{pH}$ entre 6,3 e 6,5 e sua salinidade é média a elevada (ALMEIDA, 2005). Entre as suas principais características da serragem destacam-se a elevada capacidade de troca de cátions, boa drenagem, baixa capacidade de absorção de água e pH baixo, com índice de acidez igual a 3,7 (GONÇALVES, 1995). A turfa do gênero Sphagnum tem como principais características a leveza, $\mathrm{pH}$ ácido, alta capacidade de retenção de água (BONETTI, 1992), baixa drenagem, fácil manuseio e ser estéril (GONÇALVES, 1992). Além do material de origem orgânica, existe o material de origem mineral, como a perlita, que pode ser utilizada como substrato para plantas, individualmente ou em combinação com material orgânico ou sintético, como a espuma fenólica. De origem vulcânica, a perlita tem alta porosidade e alta capacidade de retenção de água, e seu pH está entre 7,0 e 7,5 (MELO; BORTOLOZZO; VARGAS, 2006).

Por suas características físico-químicas diferenciadas, o substrato pode afetar a formação e a produção de mudas, com vantagens ou desvantagens em função da espécie frutífera com a qual se está trabalhando, tornando necessário definir para cada espécie o melhor substrato, ou mescla a ser usada. Dificilmente um material reúne todas as características apropriadas às necessidades das plantas, sendo prática frequente o uso de misturas que permitam obter as propriedades buscadas (SCHUCH et al., 2007; FISCHER et al., 2008; DAMIANI; SCHUCH, 2009).

O crescimento da exploração comercial da cultura do mirtileiro, determina a importância do conhecimento e de estudos sobre a espécie, com geração de novas técnicas que possibilitem avanços tecnológicos para produção (BRYLA et al., 2008; SILVEIRA et al., 2010; BRYLA et al., 2011) e propagação da mesma (DAMIANI et al., 2009). O objetivo deste trabalho foi verificar a viabilidade e definir um substrato adequado para o enraizamento de microestacas e o crescimento de mudas de mirtileiro cultivar Georgiagem.

\section{MATERIAL E MÉTODOS}

O trabalho foi conduzido no campo experimental da Sede da Embrapa Clima Temperado, Pelotas-RS, nos meses de dezembro de 2007 e janeiro de 2008. Foi construído um jardim microclonal a partir de mudas de mirtileiro, oriundas de material micropropagado da cultivar Georgiagem. As mudas foram mantidas em vasos de $6 \mathrm{~L}$ e acondicionadas em ambiente protegido, usando, como substrato, acícula de pínus e solo (1:1) (RISTOW et al., 2009). Foram realizadas adubações mensais com $250 \mathrm{~mL}$ de solução nutritiva ácida (pH 2,8), composta por sulfato de amônio (12\%), ureia (35\%), sulfato de potássio $(10 \%)$, sulfato de magnésio $(10 \%)$ e ácido fosfórico $(10 \%)$. A irrigação foi realizada através de gotejamento, sendo aplicada duas vezes ao dia, totalizando $200 \mathrm{~mL}$ de água/dia/vaso.

As microestacas foram coletadas na primeira quinzena de dezembro, no período da manhã. $\mathrm{O}$ material vegetal foi mantido em recipiente, com a base dos ramos imersos em água, a fim de evitar desidratação. As microestacas foram retiradas da parte intermediária do ramo, com 3-5 cm de comprimento, nos quais foram mantidas duas folhas, cada uma delas reduzidas em $50 \%$ de sua área foliar e realizada uma pequena lesão lateral na casca para que ocorra maior absorção da água e do regulador de crescimento. As microestacas foram submersas em solução com fungicida de contato Mancozeb $\left(0,5 \mathrm{~g} \mathrm{~L}^{-1}\right)$. Após, as microestacas foram submetidas ao tratamento com AIB com ácido indolbutírico $\left(2000 \mathrm{mg} \mathrm{kg}^{-1}\right)$ na forma de pó e, subsequentemente, estaqueadas nos diferentes substratos de enraizamento, sendo eles: turfa de musgo Sphagnum sp. (TF), perlita expandida (P), fibra de coco (FC), serragem (S), turfa + perlita (1:1), turfa + fibra de coco + perlita $(1: 1: 1)$ e turfa + serragem + perlita $(1: 1: 1)$.

As microestacas foram dispostas em bandejas de 24 células $(20 \mathrm{~mL})$ colocadas dentro de caixas de politereftalato de etileno (PET), as quais foram colocadas em sacos plásticos transparentes e fechados para a formação de um microambiente úmido (RISTOW, 2009) e, em seguida, mantidos em câmara de crescimento regulada para 18 horas de luz e temperatura de $25^{\circ} \mathrm{C}$. Os substratos usados foram umedecidos previamente na capacidade de campo, usando água com $\mathrm{pH} 4,5$, corrigido com ácido acético. Foi monitorada a umidade do substrato, sendo umedecido quando necessário, com o auxílio de borrifador de água, tomando cuidado para não haver falta ou excesso de umidade no substrato. Ao final de 48 dias, foram avaliadas as variáveis: a) percentual de microestacas enraizadas; b) percentual de 
microestacas com formação de calo; c) percentual de microestacas mortas; d) percentual de microestacas com necrose na base; e) percentual de microestacas verdes, correspondentes àquelas microestacas que não formaram raízes ou calos, mas que permaneceram viáveis até a avaliação; f) percentual de microestacas com brotação; g) percentual de desfolhamento das microestacas; h) comprimento da maior raiz (cm); e i) comprimento da maior brotação $(\mathrm{cm})$.

O delineamento experimental foi o inteiramente casualizado, composto por sete tratamentos (substratos) e quatro repetições, com 12 microestacas por repetição. Os dados percentuais foram transformados para arcosseno da raiz quadrada de $\mathrm{x} / 100$. Os dados foram submetidos à análise de variância, e as médias foram comparadas entre si, pelo teste de ScottKnott, a 5\% de probabilidade, por meio do software SISVAR (FERREIRA, 2000).

\section{RESULTADOS E DISCUSSÃO}

Observou-se efeito do substrato sobre o enraizamento de microestacas de mirtileiro (Figura 1), concordando com resultados obtidos por Damiani et al. (2009). A porcentagem de enraizamento foi significativamente superior para os substratos turfa de musgo e as misturas turfa + perlita, turfa + perlita + fibra de coco e turfa + perlita + serragem, variando entre 83 e $89 \%$. Por outro lado, o enraizamento nos substratos perlita, fibra de coco e serragem foram significativamente inferiores aos obtidos pelos demais, com 56; 52 e 37\%, respectivamente. Castrillón et al. (2008), em trabalho realizado com enraizamento de Vaccinium meridionale Swartz., obtiveram os melhores resultados utilizando o substrato turfa + solo e solução de $200 \mathrm{mgL}^{-1}$ de AIB, resultado semelhante ao encontrado neste trabalho.

Os resultados obtidos para o comprimento da maior raiz foram semelhantes aos encontrados para o percentual de enraizamento (Tabela 1), sendo que o comprimento foi significativamente superior para os substratos turfa de musgo e as misturas, turfa + perlita + fibra de coco e turfa + perlita + serragem, seguido dos substratos turfa + perlita e fibra de coco. Portanto, os substratos influenciaram na qualidade das raízes formadas e na percentagem de enraizamento. Esses resultados podem estar associados às condições físicas e ao $\mathrm{pH}$ dos substratos, favorecendo a emissão de raízes. Segundo Bastos et al. (2007), as características físicas e algumas características químicas dos substratos podem influenciar na formação e no crescimento inicial das plantas, tais como o pH.

Observou-se que houve uma correlação positiva estabelecida entre o enraizamento e a percenta- gem de microestacas brotadas e o comprimento das brotações, em que os melhores resultados encontrados quanto ao enraizamento foram observados também para a brotação e o comprimento de brotação. Esses resultados podem estar associados ao sistema radicular maior que é capaz de aumentar a captação de água e nutrientes, resultando na formação de novos tecidos e na biossíntese das auxinas, os quais irão promover maior crescimento da planta. Segundo Taiz e Zeiger (2006), as auxinas são sintetizadas nos meristemas, portanto a ação conjunta do substrato e AIB geraram em maior crescimento radicular.

Para o sucesso da cultura do mirtileiro, o pH do solo deve ser ácido $(4,0$ a 5,2), conter elevado teor de matéria orgânica (superior a 5\%) e ter boa retenção de umidade e drenagem (BRYLA et al., 2011; PANNUNZIO et al., 2011). Da mesma forma, na fase de propagação da planta e crescimento das mudas, há necessidade do uso de substratos com reação ácida e de textura leve (SCHUCH et al., 2007).

Fischer et al. (2008) recomendam que o pH do substrato deva ser verificado para a formação de mudas de mirtileiro a partir de estacas lenhosas, pois, em substratos com $\mathrm{pH}$ superior a 6,5 , as estacas apresentam dificuldades de enraizamento. Barra (2008), ao testar diferentes substratos, constatou que o pH não foi limitante no crescimento de mudas de mirtileiro, sendo que os valores do $\mathrm{pH}$ variaram entre 4,10 a 6,11 .

Em geral, quando se usaram os substratos turfa e fibra de coco, esses permitiram a obtenção de melhores resultados. Essa superioridade pode ser explicada devido às características desses substratos. Cabe salientar que os componentes dos substratos e misturas com turfa e fibras de coco possuem como característica física porosidade alta. No caso da turfa, a porosidade fica em torno de $95 \%$, e a fibra de coco, valores superiores a $80 \%$ (BARRA, 2008).

Os elevados percentuais de enraizamento nas misturas com perlita podem ser atribuídos às suas características, como a alta porosidade, melhorando as características físicas das misturas e oferecendo menor resistência ao crescimento radicular, além de possuir a capacidade de manter a temperatura e a umidade do substrato. Damiani e Schuch (2009) observaram que o uso da perlita favoreceu o crescimento e o alongamento das raízes de mirtileiro e constataram que esse resultado pode ser atribuído à característica de elevado grau de porosidade da perlita, evitando a compactação do substrato e a menor resistência ao desenvolvimento radicular.

Quanto à formação de calo na base das microestacas (Tabela 1), observou-se que essa variável apresenta diferenças significativas em fun- 
ção do substrato. A utilização de substratos puros (serragem, perlita, fibra de coco e turfa) estimula a formação do calo, respectivamente, em $25 ; 20 ; 10$ e $4 \%$. Por outro lado, a turfa, que apresentou o menor percentual de calo dos substratos puros, quando combinada com substratos porosos, turfa + perlita e turfa + perlita + fibra de coco, apresenta completa redução da formação de calo $(0 \%)$. Porém, apesar de a combinação de turfa com substratos porosos ser efetiva na redução de calo, esta afirmativa não é válida para a mistura com perlita + serragem, o que provavelmente se deve ao fato de a serragem causar o maior percentual de formação de calo $(25 \%)$.

Com relação à origem das raízes formadas, visualmente foi possível observar que as mesmas se formaram a partir da lesão e não das células do calo formado, indicando que as mesmas se desenvolveram diretamente da região meristemática do câmbio vascular, concordando com os dados obtidos por Schuch et al. (2007) e Trevisan et al. (2008).

A avaliação do percentual de formação de necrose na base das microestacas diferiu estatisticamente apenas para o substrato turfa + perlita + serragem, o qual não apresentou formação de necrose. Neste mesmo substrato, além do elevado percentual de enraizamento ( $85 \%$ ), verificou-se, também, o maior comprimento de raiz $(4,66 \mathrm{~cm})$. Da mesma forma, estes resultados devem estar ligados às condições físicas e químicas desses substratos, favorecendo a atividade celular durante o processo de formação de calos e da emissão de raízes, assim como o crescimento radicular. Com relação ao percentual de microestacas viáveis, correspondentes àquelas estacas que não formaram raízes ou calos, mas que permaneceram com coloração verde até a avaliação, não houve diferença significativa entre os substratos testados (Tabela 1).

Para a variável, percentual de microestacas com brotações, verificou-se que, independentemente dos substratos, apesar de estatisticamente haver diferença entre os mesmos, a capacidade de emissão de brotações foi inferior a $50 \%$, sendo observado um máximo de $35 \%$ e um mínimo de $10 \%$. Os maiores comprimentos das brotações $(\mathrm{cm})$ foram obtidos com os substratos turfa + perlita e turfa + perlita + fibra de coco (Tabela 1), os quais apresentaram os melhores índices de enraizamento, nenhuma formação de calo e raízes bem desenvolvidas.

$\mathrm{O}$ uso da fibra de coco em misturas de substratos tem sido recomendado devido a seus bons resultados na propagação. A fibra de coco é usada na propagação de estacas herbáceas de figueira oriundas de desbrota, e sua eficiência é explicada pelas características físicas desse substrato (PIO et al., 2005). Barra (2008), ao testar misturas da agroindústria com turfa e fibra de coco para a propagação de mirtileiro das cultivares Brigitta e Marimba, observou que as misturas com maior proporção desses substratos apresentaram os melhores resultados.

A capacidade de enraizamento de uma espécie depende do seu potencial genético, do estado fisiológico da matriz doadora das estacas, do estado fitossanitário, do tipo de estaca, bem como do substrato utilizado. O substrato, no enraizamento de estacas, desempenha importante função, principalmente para as espécies que possuem dificuldades em emitir raízes, como é o caso do mirtileiro. O sistema radicular do mirtileiro é superficial, constituído de raízes finas, fibrosas e de pouca extensão, além de ser desprovido de pelos radiculares. Dessa forma, as características físicas do substrato são importantes na propagação de mirtileiro, o qual deve ser suficientemente poroso, a fim de permitir trocas gasosas eficientes, oferecer resistência à compactação, favorecendo a respiração das raízes e a atividade dos microrganismos do meio.

O uso dos condicionantes de substratos é importante, pois dificilmente se encontra um material com todas as características positivas para uso como substrato, sendo necessário melhorar as propriedades do meio de cultivo. Diante dos substratos testados neste experimento, a turfa, a perlita e a fibra de coco mostraram-se bons componentes para as misturas de substratos recomendados para a produção de mudas de mirtileiro. 


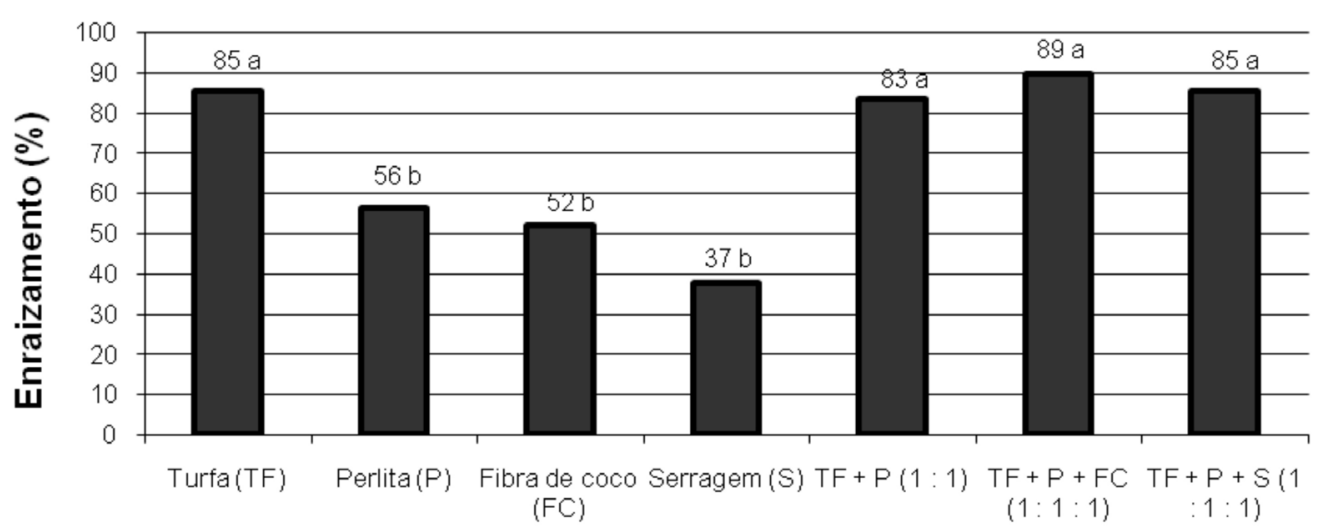

\section{Substratos}

FIGURA 1 - Porcentagem de enraizamento de mirtileiro cultivar Georgiagem sob o efeito de diferentes substratos. Embrapa Clima Temperado, Pelotas - RS, 2010.

TABELA 1 - Porcentagem de formação de calo, necrose na base, microestacas viáveis, comprimento de maior raiz, brotação e comprimento médio da maior brotação do mirtileiro cultivar Georgiagem sob o efeito de diferentes substratos. Embrapa Clima Temperado, Pelotas - RS, 2010.

\begin{tabular}{lcccccc}
\hline Tratamentos & $\begin{array}{c}\text { Formação } \\
\text { de calo (\%) }\end{array}$ & $\begin{array}{c}\text { Necrose na } \\
\text { base (\%) }\end{array}$ & $\begin{array}{c}\text { Viáveis } \\
\mathbf{( \% )}\end{array}$ & $\begin{array}{c}\text { Comprimento } \\
\text { maior raiz } \mathbf{( c m )}\end{array}$ & $\begin{array}{c}\text { Brotação } \\
(\mathbf{\%})\end{array}$ & $\begin{array}{c}\text { Comprimento } \\
\text { brotação (cm) }\end{array}$ \\
\hline Turfa (TF) & $4,17 \mathrm{~b}$ & $10,41 \mathrm{a}$ & 0 & $4,05 \mathrm{a}$ & $35,42 \mathrm{a}$ & $1,02 \mathrm{~b}$ \\
Perlita (P) & $20,83 \mathrm{a}$ & $16,67 \mathrm{a}$ & 6,25 & $1,86 \mathrm{c}$ & $10,41 \mathrm{~b}$ & $0,93 \mathrm{~b}$ \\
Fibra coco (FC) & $10,41 \mathrm{a}$ & $27,08 \mathrm{a}$ & 6,25 & $3,04 \mathrm{~b}$ & $12,50 \mathrm{~b}$ & $0,96 \mathrm{~b}$ \\
Serragem (S) & $25 \mathrm{a}$ & $22,92 \mathrm{a}$ & 14,58 & $1,90 \mathrm{c}$ & $22,92 \mathrm{a}$ & $1,11 \mathrm{~b}$ \\
TF + P & $0 \mathrm{~b}$ & $14,58 \mathrm{a}$ & 2,08 & $3,50 \mathrm{~b}$ & $20,83 \mathrm{a}$ & $1,86 \mathrm{a}$ \\
TF + P + FC & $0 \mathrm{~b}$ & $10,41 \mathrm{a}$ & 0 & $3,89 \mathrm{a}$ & $35,41 \mathrm{a}$ & $2,50 \mathrm{a}$ \\
TF + P + S & $16,66 \mathrm{a}$ & $0 \mathrm{~b}$ & 2,08 & $4,66 \mathrm{a}$ & $27,09 \mathrm{a}$ & $1,02 \mathrm{~b}$ \\
\hline Média Geral & 10,41 & 14,58 & 4,46 & 3,27 & 23,51 & 1,35 \\
CV (\%) & 73,33 & 45,31 & 152,29 & 11,03 & 33,39 & 28,66 \\
\hline
\end{tabular}

*Médias seguidas pelas mesmas letras na coluna não diferem entre si, pelo teste de Scott-Knott $(\mathrm{P} \leq 0,05)$.

$\mathrm{NS}=$ não significativo

\section{CONCLUSÕES}

1-Os melhores substratos para o enraizamento de microestacas de mirtileiro são a turfa de musgo Sphagnum e as misturas turfa + perlita, turfa + perlita + fibra de coco e turfa + perlita + serragem

2-A técnica de microestaquia é eficiente na propagação do mirtileiro da cultivar Georgiagem.

\section{REFERÊNCIAS}

ALMEIDA, L. S. Avaliação morfológica de mudas de Allophylus edulis (A. St. Hill., A. Juss. e Cambess.) Radl. (Vacum) e Schinus terebinthifolius Raddi (Aroeira) produzidas em diferentes substratos. 96 f. Dissertação (Mestrado em Ciências Florestais) - Universidade Federal do Paraná, Curitiba, 2005.

ANTUNES, L.E.C.; GONÇALVES, E.D.; RISTOW, N.C.; CARPENEDO, S.; TREVISAN, R. Fenologia, produção e qualidade de frutos de mirtilo. Pesquisa Agropecuária Brasileira, Brasília, v.43, n.8, p.1011-1015, 2008. 
BARRA, C.M.S. DE LA. Evaluación de mezclas de residuos orgânicos bioprocesados y otros materiales, para la propagación de arándanos. 2008. 53f. Monografia (Escuela de Agronomía) - Faculdad de Ciencias Agronómicas, Santiago, 2008.

BASTOS, D.C.; PIO, R.; SCARPARE FILHO, A.; LIBARDI, M.N.; ALMEIDA, L.F.P. de; ENTELMANN, F.A. Diferentes substratos na produção de porta-enxertos de caramboleira. Ciência e Agrotecnologia, Lavras, v.31, n.2, p.312-316, 2007.

BONETTI, E.J. Alguns substratos utilizados na propagação de espécies ornamentais, estacas e sementes. Lavras: ESAL, 1992. 9 p.

BRYLA, D. R.; GARTUNG, J. L.; STRIK, B.C. Evaluation of irrigation methods for highbush blueberry - I. growth and water requirements of young plants. HortScience, Alexandria, v.46, p.95-101, 2011.

BRYLA, D. R.; LINDERMAN, R. G.; YANG, W. Q. Incidence of phytophthora and pythium infection and the relation to cultural conditions in commercial blueberry fields Hortscience, Alexandria, v. 43, n. 1, p. 260-263, 2008.

CASTRILLÓN, J.C.; CARVAJAL, E.; LIGARRETO, G.; MAGNITSKIY, S. El efecto de auxinas sobre el enraizamiento de las estacas de agraz (Vaccinium meridionale Swartz) em diferentes sustratos. Agronomía Colombiana, Bogotá, v.26, n.1, p.16-22, 2008.

DAMIANI, C. R.; PELIZZA, T. R.; SCHUCH, M. W.; RUFATO, A. R. Luminosidade e IBA no enraizamento de microestacas de mirtileiro dos grupos rabbiteye e southern highbush. Revista Brasileira de Fruticultura, Jaboticabal, v.31, n.3, p. 650-655, 2009.

DAMIANI, C. R.; SCHUCH, M. W. Enraizamento in vitro de mirtilo em condições fotoautotróficas. Ciência Rural, Santa Maria, v.39, n.4, p. 10121017, 2009.

DUTRA, L. F.; WENDLING, I. Micropropagação e microestaquia de eucalipto. In: WENDLING, I.; DUTRA, L. F. Produção de mudas de eucalipto. Colombo: Embrapa Florestas, 2010. p. 81-119.
FERREIRA, D.F. Análise estatística por meio do SISVAR (Sistema para Análise de Variância) para Windows versão 4.0. In: REUNIÃO ANUAL DA REGIÃO BRASILEIRA DA SOCIEDADE INTERNACIONAL DE BIOMETRIA, 2000, São Carlos. Anais... São Carlos: UFSCar, 2000. cap.3, p.255- 258 .

FISCHER, D.L. de O. et al. Efeito do ácido indolbutírico e da cultivar no enraizamento de estacas lenhosas de mirtilo. Revista Brasileira de Fruticultura, Jaboticabal, v.30, n.2, p. 285-289, 2008.

GONÇALVES, A.L. Características de substratos. In: CASTRO, C.E.F. de; ANGELIS, B.L.D. de; MOURA L.P.P. de et al. Manual de floricultura. Maringá: SBFPO, 1992. p. 44-52.

GONÇALVES, A.L. Substratos para produção de mudas de plantas ornamentais. In: MINAMI, K. (Ed). Produção de mudas de alta qualidade em horticultura. São Paulo: Queiroz, 1995. p. 107-115.

LIGARRETO, G.A.; MEDINA, C.I.; ARIAS, M.L.; MARTÍNEZ, L.J.; CORREDOR, H.; MUÑOZ, J.D.; PATIÑO, P. Zonificación de las espécies de agraz (Vaccinium spp.) y uma aproximación de su manejo agronômico como cultivos promisorios para la zona alto andina colombiana: segundo informe de actividades. Bogotá: Facultad de Agronomía, Universidad Nacional de Colômbia, 2006. 26p.

MELO, G.W.B.; BORTOLOZZO, A.R.; VARGAS, L. Substratos. In: ADALECID, K. et al. Produção de morangos no sistema semi-hidropônico. Bento Gonçalves: Embrapa Uva, 2006. Disponível em: $<$ http://sistemasdeproducao.cnptia.embrapa.br/ FontesHTML/Morango/MorangoSemiHidroponico/ substratos.htm>. Acesso em: 23 abr. 2011.

PANNUNZIO, A.; VILELLA, F.; TEXEIRA, P.; PREMUZIK, Z. Impacto de los sistemas de riego por goteo en arándanos. Revista Brasileira de Engenharia Agrícola e Ambiental, Campina Grande, v.15, n.1, p. 03-08. 2011.

PIO, R.; ARAÚJO, J.P.C.de; BASTOS, D.C.; ALVES, A.S.R.; ENTELMANN, F.A.; SCARPARE FILHO, J.A.; MOURÃO FILHO, F. de A.M. Substratos no enraizamento de estacas herbáceas de figueira oriundas da desbrota. Ciência e Agrotecnologia, Lavras, v. 29, n. 3, p. 604-609, 2005. 
RISTOW, N. C. Multiplicação de mirtileiro (Vaccinium spp.) por estaquia. 2009. 85 f. Tese (Doutorado em Agronomia) - Faculdade Eliseu Maciel, Universidade Federal de Pelotas, Pelotas, 2009.

RISTOW, N.C.; ANTUNES, L.E.C.; SHUCH, M.W.; TREVISAN, R.; CARPENEDO, S. Crescimento de plantas de mirtilo a partir de mudas micropropagadas. Revista Brasileira de Fruticultura, Jaboticabal, v. 31, p. 210-215, 2009.

SANTOS, A.M. Situação e perspectivas do mirtilo no Brasil. In: SIMPÓSIO NACIONAL DO MORANGO, 2., E ENCONTRO DE PEQUENAS FRUTAS E FRUTAS NATIVAS DO MERCOSUL, 1., Pelotas. Palestras... Pelotas: Embrapa Clima Temperado, 2004. p.282-285.

SCHUCH, M. W.; DAMIANI, C. R.; SILVA, L. C. da; ERIG, A. C. Micropropagação como técnica de rejuvenescimento em mirtilo (Vaccinium ashei Reade) cultivar Climax. Ciência e Agrotecnologia, Lavras, v.32, n.3, p. 814-820, 2008.

SCHUCH, M. W.; De ROSSI, A.; DAMIANI, C. R.; SOARES, G. C. AIB e substrato na produção de mudas de mirtilo cv. "Climax" através de microestaquia. Ciência Rural, Santa Maria, v. 37, n. 5, p. 1446-1449, 2007.

SILVEIRA, T. M. T.; RASEIRA, M. C. B.; NAVA, D. E.; COUTO, M. Influência do dano da abelha-irapuá em flores de mirtileiro sobre a frutificação efetiva e as frutas produzidas. Revista Brasileira de Fruticultura, Jaboticabal, v.32, n.1, p. 303-307, 2010.
TAIZ, L.; ZEIGER, E. Fisiologia vegetal. 3.ed. Porto Alegre: Artmed, 2006, 719p.

TREVISAN, R.; FRANZON, R.C.; FRITSCHE NETO, R.; GONÇALVES, R. S.; GONÇALVES, E. D.; ANTUNES, L. E. C. Enraizamento de estacas herbáceas de mirtilo: influência da lesão na base e do ácido indolbutírico. Ciência e Agrotecnologia, Lavras, v.32, n.2, p. 402-406. 2008.

WENDLING, I.; DUTRA, L. F. Produção de mudas de eucalipto por estaquia e miniestaquia. In: WENDLING, I.; DUTRA, L. F. Produção de mudas de eucalipto Colombo: Embrapa Florestas, 2010. cap. 2 , p. $50-80$.

WENDLING, I.; GATTO, A. Substratos, adubação e irrigação na produção de mudas. Viçosa: Aprenda Fácil, 2002.

WILLIAMSON, J. G.; MILLER, E.P. Effects of fertilizer rate and form on vegetative growth and yield of southern highbush blueberry in pine bark culture. HortTechnology, Alexandria, v. 19, p. 152-157, 2009.

XIE, Z. S.; TONG, S. J. Studies on substrates for blueberry cultivation. Acta Horticulturae, Wageningen , n.186, v. 2, p. 513-520, 2009. 